\title{
Sexual orientation, social capital and daily tobacco smoking: a population-based study
}

\author{
Martin Lindström ${ }^{1,2^{*}}$, Jakob Axelsson ${ }^{1,2}$, Birgit Modén ${ }^{1,2}$ and Maria Rosvall ${ }^{1,2}$
}

\begin{abstract}
Background: Studies have suggested poorer health in the homosexual and bisexual groups compared to heterosexuals. Tobacco smoking, which is a health-related behavior associated with psychosocial stress, may be one explanation behind such health differences. Social capital, i.e. the generalized trust in other people and social participation/social networks which decreases the costs of social interaction, has been suggested to affect health through psychosocial pathways and through norms connected with health related behaviours, The aim of this study is to investigate the association between sexual orientation and daily tobacco smoking, taking social capital into account and analyzing the attenuation of the logit after the introduction of social participation, trust and their combination in the models.
\end{abstract}

Methods: In 2008 a cross-sectional public health survey was conducted in southern Sweden with a postal questionnaire with 28,198 participants aged $18-80$ (55\% participation rate). This study was restricted to 24,348 participants without internally missing values on all included variables. Associations between sexual orientation and tobacco smoking were analyzed with logistic regression analysis.

Results: Overall, $11.9 \%$ of the men and $14.8 \%$ of the women were daily tobacco smokers. Higher and almost unaltered odds ratios of daily smoking compared to heterosexuals were observed for bisexual men and women, and for homosexual men throughout the analyses. The odds ratios of daily smoking among homosexual women were not significant. Only for the "other" sexual orientation group the odds ratios of daily smoking were reduced to not significant levels among both men and women, with a corresponding 54\% attenuation of the logit in the "other" group among men and 31.5\% among women after the inclusion of social participation and trust. In addition, only the "other" sexual orientation group had higher odds ratios of low participation than heterosexuals.

Conclusions: Bisexual men and women and homosexual men, but not homosexual women, are daily smokers to a higher extent than heterosexuals. Only for the "other" sexual orientation group the odds ratios of daily smoking were reduced to not significant levels after adjustments for covariates including trust and social participation.

Keywords: Social capital, Sexual orientation, Tobacco smoking, Trust, Sweden

\section{Background}

One important health policy goal is to reduce health differences between population groups in society. Health differences between population groups not only concern socioeconomic differences in health but are also defined according to gender, ethnicity, and sexual orientation. Studies in the USA [1,2], Australia [3], Europe [4] and Sweden [5] suggest poorer health in the bisexual and homosexual groups compared to heterosexuals.

\footnotetext{
* Correspondence: martin.lindstrom@med.lu.se

${ }^{1}$ Social Medicine and Health Policy Department of Clinical Sciences, Malmö

University Hospital, Lund University, Malmö S-205 02, Sweden

${ }^{2}$ Centre for Economic Demography, Lund University, Lund, Sweden
}

Discrimination, prejudice, threat of violence and violence may explain these health differences according to sexual orientation [6,7], which was also demonstrated in a previous study were we demonstrated significantly higher odds ratios of poor self rated health among bisexual, homosexual and "other" men as well as bisexual and "other" women compared to heterosexual men and women, respectively. These differences disappeared after the introduction of generalized trust in other people, experience of having been offended during the past three months, experience of threat of violence during the past twelve

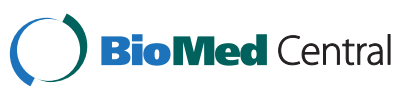

(c) 2014 Lindström et al.; licensee BioMed Central Ltd. This is an Open Access article distributed under the terms of the Creative Commons Attribution License (http://creativecommons.org/licenses/by/2.0), which permits unrestricted use, distribution, and reproduction in any medium, provided the original work is properly credited. The Creative Commons Public Domain Dedication waiver (http://creativecommons.org/publicdomain/zero/1.0/) applies to the data made available in this article, unless otherwise stated. 
months and experience of violence during the past twelve months in multiple logistic regression models [7].

Differences in health related behaviours and particularly tobacco smoking prevalence may also explain health differences between population segments with different sexual orientation [8]. Most earlier studies on tobacco smoking among sexual minorities have only compared sexual minority groups with each other [9], collapsed the bisexual and homosexual groups when comparing with heterosexuals [10], or exclusively studied women $[11,12]$. Only one study including adults compared the homosexual and bisexual groups with heterosexuals, and found higher smoking rates for homosexual men and women and bisexual women [13]. In a UK study of adolescents aged 18-19 it was found that lesbian or gay participants were twice as likely to have a history of cigarette smoking, and bisexuals had nearly double likelilood of ever having smoked compared to heterosexual participants. Adjustment for ethnic minority status and parental socioeconomic status did not substantially alter the results. Similar results were found when combining the minority groups and comparing them with heterosexuals [14]. Despite decades of decreasing prevalence of tobacco smoking in Sweden, tobacco smoking with its relatively increasing socioeconomic gradient is still an important contributor to socioeconomic differences in health among both men and women [5]. This is due to the fact that tobacco smoking behaviours in general, as well as decisions to take up smoking or quit smoking in particular, are complex phenomena determined by psychological, economic, social and psychosocial factors $[15,16]$, which e.g. include factors such as emotional support and instrumental support and social capital [17]. Daily smoking is thus associated not only with age, sex, country of birth [18] and socioeconomic status but also with emotional support and instrumental support [17]. Previous studies have shown sex differences in the association between sexual minority status and daily smoking (see e.g. 13), and sex differences in daily smoking exist in the general population in Sweden as well as in most other countries [19], which is the rationale for stratifying by sex in this study.

In the past fifteen to twenty years social capital has been suggested as an important health determinant, although there is still an ongoing debate concerning both the definition and the contents of the concept. Some authors define social capital as social structures, social networks, social relationships and/or institutionalized relationships [20,21]. These authors also sometimes put emphasis on the possibility for individuals to achieve their personal goals in terms of power and resources within networks by excluding trust and reciprocity from the social capital concept [20]. Other authors define social capital as social structures/relationships/networks and trust. This second group of authors also tend to put more emphasis on lowering the costs of social interaction by including trust as well as social networks in the concept $[22,23]$. By including both generalized trust in other people and social participation/social network in this study we theoretically adhere to the second group of authors such as Coleman and Putnam, and emphasize the lowering of social interaction costs for sexual minority groups. We thus regard social capital as mediator between sexual orientation and daily tobacco smoking. Social capital has been suggested to affect health through psychological and psychosocial pathways, through norms and attitudes connected with health related behaviours, through access to health care and amenities, and through crime [24]. Both trust and social participation have been shown to be associated with tobacco smoking [25-27], and plausible pathways connecting social capital and smoking in a causal relationship include at least the two first of the four pathways listed above. Our previous study based on the public health survey in Skåne, southern Sweden in 2008 also showed higher odds ratios of low trust in the bisexual and "other" groups compared to heterosexuals among both men and women, a pattern which may be caused by discrimination, prejudice and social exclusion [7], but this previous study did not include social participation, the other major component of social capital.

Our hypotheses are that tobacco smoking is significantly more prevalent in the sexual minority groups than among heterosexuals among both men and women, and that low social participation is significantly more prevalent in the bisexual and "other" sexual minority groups than among heterosexuals among both men and women, given the fact that we have shown that low trust is more common in these groups. The aim of this study is thus to investigate and replicate the previously found association between sexual orientation and daily tobacco smoking, and include emotional support, instrumental support, generalized trust in other people and social participation in the analyses in order to explore possible explanatory variables behind these already known associations. An additional aim is to investigate the association between sexual orientation and social participation.

\section{Methods}

\section{Study population}

The public health survey in 2008 regarding public health in Skåne, southern Sweden, is a cross sectional study. It is based on a random (weighted) sample of people in Skåne drawn from the public population registers. In August to September 2008, a total of 28,198 persons answered the postal questionnaire, which represents roughly a $55 \%$ response rate. Two reminder letters were also sent to initial non-respondents. In this study, the 
number of participants has been restricted to participants with values on all the variables included in the multiple logistic regression analyses (no internally missing values), which means that the number analysed is a total 24,348 of which 11,084 are men and 13,264 women. Ethical approval was granted by the Ethical Committee, Lund University, Sweden.

\section{Definitions}

\section{Dependent variable}

Daily tobacco smoking was assessed by the question "Do you smoke?" which included three alternative answers "Yes, daily", "Yes, but not daily" and "No". In the analyses this variable was dichotomized by collapsing the two latter alternatives.

\section{Independent variables}

Sexual orientation was retrieved by the item "Do you regard yourself today as 1) heterosexual, 2) bisexual, 3) homosexual, 4) other?"

Age was categorized into the age strata 18-24, 25-34, $35-44,45-54,55-64$ and $65-80$ years.

Stratification by sex was conducted in the analyses.

\section{Born in Sweden/born in other country than Sweden}

Participants born outside Sweden were aggregated into one group which was compared to participants born in Sweden.

Socioeconomic status (by occupation) included the categories employed on the labour market higher nonmanual employees, medium level non-manual employees, low level non-manual employees, skilled manual workers, unskilled manual workers and self-employed and farmers. The groups outside the workforce (without occupation) consists of early retired (before age 65, for health or early retirement entitlement in the employment contract reasons), unemployed, students, old age pensioners above age 65, unclassified and long term sick leave.

Emotional support was measured with the item "Do you feel that you have someone or some persons who can give you proper personal support to cope with the stress and problems of life?" which had four alternatives answers: "Yes, I am absolutely certain to get such support", "Yes, possibly", "'Not certain", and "No". The three latter were collapsed as low emotional support.

Instrumental support was retrieved with the question "Can you get help by some or several persons in case of illness or practical problems (borrow minor items, help with reparation, help to write a letter, getting advice or information)?" which contained the same alternatives as the emotional support item, and was dichotomized accordingly.

Generalized trust in other people assesses the individual's level of generalized trust in other people. It was appraised by the item "Generally, you can trust other people" which entails the four answer alternative: "Do not agree at all", "Do not agree", "Agree", and "Completely agree". These were dichotomized, the two first alternatives denoting low trust and the two latter denoting high.

Social participation assesses whether the respondent has taken part in the activities of formal and informal groups in society (study circle/course at workplace, other study circle/course, union meeting, meeting in other organizations, theatre/cinema, arts exhibition, church, sports event, letter to the editor of a newspaper/journal, demonstration, night club/entertainment, big gathering of relatives, private party). It is measured as an index of 13 items and dichotomized with three or less alternatives depicting low social participation, and four or more alternatives high.

\section{Analysis}

Correlation coefficients (bivariate Pearson's r) between emotional support, instrumental support, generalized trust in other people and social participation were calculated in order to discern psychometric independence. Prevalences (\%) of daily smoking, age, birth country, socioeconomic status, emotional support, instrumental support, trust, social participation, and sexual orientation stratified by sex were assessed (Table 1). Prevalences (\%) and odds ratios with 95\% confidence intervals (OR:s, 95\% CI) of daily smoking were calculated according to sexual orientation, age, birth country, socioeconomic status, emotional support, instrumental support, trust and social participation (Table 2). Prevalences (\%), crude and age-adjusted odds ratios and $95 \%$ confidence intervals of social participation were calculated according to sexual orientation (Table 3). Age-adjusted and multiple adjusted odds ratios and 95\% confidence intervals of daily tobacco smoking were calculated regarding sexual orientation. (Table 4). The attenuation of the logit for the association between the sexual orientation and daily smoking after the inclusion in the logistic regression model already containing age, country of birth and socioeconomic status (stratified for sex) of the social capital variables generalized trust in other people, social participation and their combination was calculated (not shown in Table 4). All tables were stratified by sex. The odds ratios in Tables 2, 3, 4 were calculated in logistic regression models. The statistical analyses were performed using the SPSS software package version 22.0 [28].

\section{Results}

All correlations between the social support and social capital variables were low, with the exception of the correlation coefficient (bivariate Pearson's $r$ ) between 
Table 1 Prevalence (\%) of tobacco smoking, demographic characteristics, socioeconomic status, emotional support, instrumental support, generalized trust in other people, social participation and sexual orientation

\begin{tabular}{|c|c|c|c|}
\hline & $\begin{array}{c}\text { Men } \\
(n=11,084)\end{array}$ & $\begin{array}{c}\text { Women } \\
(n=13,264)\end{array}$ & $\begin{array}{c}\text { Total } \\
(n=24,348)\end{array}$ \\
\hline Daily smoking & 11.9 & 14.8 & 13.5 \\
\hline \multicolumn{4}{|l|}{ Age } \\
\hline $18-24$ & 8.6 & 9.7 & 9.2 \\
\hline $25-34$ & 13.2 & 15.3 & 14.3 \\
\hline $35-44$ & 17.3 & 18.4 & 17.9 \\
\hline $45-54$ & 18.2 & 19.4 & 18.8 \\
\hline $55-64$ & 21.4 & 19.5 & 20.4 \\
\hline $65-80$ & 21.4 & 17.8 & 19.5 \\
\hline $\begin{array}{l}\text { Born in other country than } \\
\text { Sweden }\end{array}$ & 12.0 & 12.2 & 12.1 \\
\hline \multicolumn{4}{|l|}{ Socioeconomic status (SES) } \\
\hline High non-manual & 11.2 & 9.0 & 10.0 \\
\hline Medium non-manual & 13.1 & 18.1 & 15.8 \\
\hline Low non-manual & 5.1 & 10.3 & 8.0 \\
\hline Skilled bluecollar & 11.2 & 9.1 & 10.1 \\
\hline Unskilled bluecollar & 11.7 & 11.3 & 11.5 \\
\hline Employer/farmer & 8.0 & 3.9 & 5.8 \\
\hline Early retired & 2.8 & 4.1 & 3.5 \\
\hline Unemployed & 3.0 & 3.4 & 3.2 \\
\hline Student & 5.1 & 7.0 & 6.1 \\
\hline Pensioner & 23.1 & 18.8 & 20.8 \\
\hline No information on SES & 4.8 & 3.5 & 4.1 \\
\hline Long term sick leave & 0.8 & 1.3 & 1.1 \\
\hline Low emotional support & 35.6 & 28.4 & 31.7 \\
\hline Low instrumental support & 26.8 & 21.4 & 23.8 \\
\hline Low trust & 32.8 & 34.4 & 33.7 \\
\hline Low social participation & 40.3 & 35.8 & 37.9 \\
\hline \multicolumn{4}{|l|}{ Sexual orientation } \\
\hline Heterosexual & 96.9 & 97.0 & 97.0 \\
\hline Bisexual & 1.1 & 1.5 & 1.3 \\
\hline Homosexual & 0.8 & 0.6 & 0.7 \\
\hline Other & 1.1 & 0.9 & 1.0 \\
\hline
\end{tabular}

Men $(n=11,084)$, women $(n=13,264)$, and total $(n=24,348)$. The public health survey in Skåne 2008.

emotional support and instrumental support $(\mathrm{r}=0,568)$. The correlation coefficient between emotional support and trust was 0.128 , between emotional support and social participation 0.154 , between instrumental support and trust 0.143 , between instrumental support and social participation 0.179 and between trust and social participation 0.137 .

Table 1 shows that $11.9 \%$ of the men and $14.8 \%$ of the women were daily tobacco smokers. The distribution (prevalence) for age, country of birth, socioeconomic status, emotional support, instrumental support, trust, social participation and sexual orientation are also displayed (Table 1).

Table 2 demonstrates that the odds ratios and prevalence (\%) of daily tobacco smoking in bivariate analyses were significantly higher among middle-aged respondents, respondents with lower socioeconomic status, low emotional support, low instrumental support, low trust, low social participation and among persons of bisexual and other orientation among both men and women. The group men born abroad had a higher odds ratio of daily smoking than men born in Sweden, and homosexual men also had higher odds ratios of daily smoking compared to heterosexual men.

The crude and age-adjusted odds ratios in Table 3 display that only the "other" sexual orientation group had a significantly higher prevalence of low social participation compared to the heterosexual reference group. In the age-adjusted models, the odds ratio of low social participation in the "other" sexual orientation group was 2.43 (1.67-3.53) among men and 3.21 (2.16-4.77) among women compared to the heterosexual reference group.

The higher odds ratios of daily smoking among bisexual and homosexual men compared to heterosexual men remained throughout the multiple logistic regression analyses. In the final analysis the odds ratios of daily smoking were 1.88 (1.22-2.92) among bisexual and 2.11 (1.24-3.58) among homosexual men. In contrast, the odds ratio of daily smoking became not significant already in the second model for the "other" sexual orientation category among men. Among women, the odds ratios of daily smoking for the bisexual group were also higher and almost unaltered throughout the analyses, odds ratio 1.68 (1.20-2.36) in the final model. In contrast, no statistically significant differences between homosexual and heterosexual women were observed throughout the multiple analyses, odds ratio $0.76(0.38-1.54)$ in the final model. The odds ratios of daily smoking for the "other" sexual orientation category among women were significant until social participation was added in the final model, an addition which reduced the odds ratio of daily smoking in this group from 1.59 (1.03-2.46) to 1.44 (0.93-2.23). When social participation, trust and their combination were added to the logistic regression model assessing the association between sexual orientation and daily smoking including age, country of birth and socioeconomic status (stratified for sex), only the attenuation of the logit for the "other" sexual orientation category was substantial (above $10 \%$ ) for both men and women, $20.8 \%$ for trust, $40.4 \%$ for social participation and $54.2 \%$ for their combination among men and $10.6 \%$ for trust, $26.5 \%$ for social participation and $31.5 \%$ for their combination among women. A substantial attenuation of the logit was also observed for 
Table 2 Prevalence (\%) and odds ratios (OR, $95 \% \mathrm{Cl})$ in bivariate analyses of daily tobacco smoking according to sexual orientation, age, country of birth, socioeconomic status, emotional support, instrumental support, generalized trust in other people, and social participation

\begin{tabular}{|c|c|c|c|c|}
\hline & \multicolumn{2}{|c|}{ Men $(n=11,084)$} & \multicolumn{2}{|c|}{ Women $(n=13,264)$} \\
\hline & $\%$ & OR $(95 \% \mathrm{Cl})$ & $\%$ & OR $(95 \% \mathrm{Cl})$ \\
\hline \multicolumn{5}{|l|}{ Sexual orientation } \\
\hline Heterosexual & 11.7 & 1.00 & 14.6 & 1.00 \\
\hline Bisexual & 22.2 & $2.19(1.43-3.34)$ & 23.6 & $1.81(1.30-2.51)$ \\
\hline Homosexual & 22.4 & $2.18(1.31-3.65)$ & 11.3 & $0.75(0.38-1.51)$ \\
\hline Other & 17.3 & $1.59(1.00-2.12)$ & 24.8 & $1.93(1.25-2.96)$ \\
\hline \multicolumn{5}{|l|}{ Age } \\
\hline $18-24$ & 7.8 & 1.00 & 15.0 & 1.00 \\
\hline $25-34$ & 9.3 & $1.21(0.90-1.63)$ & 12.0 & $0.77(0.63-0.95)$ \\
\hline $35-44$ & 10.7 & $1.41(1.07-1.87)$ & 13.5 & $0.89(0.73-1.08)$ \\
\hline $45-54$ & 14.4 & $1.99(1.52-2.61)$ & 19.5 & $1.38(1.15-1.65)$ \\
\hline $55-64$ & 17.0 & $2.42(1.86-3.14)$ & 17.0 & $1.16(0.97-1.40)$ \\
\hline $65-80$ & 9.0 & $1.16(0.88-1.53)$ & 10.9 & $0.69(0.57-0.85)$ \\
\hline \multicolumn{5}{|c|}{ Born in Sweden/born in other country than Sweden } \\
\hline Sweden & 10.6 & 1.00 & 14.6 & 1.00 \\
\hline Other country & 21.5 & $2.30(1.99-2.66)$ & 16.4 & $1.15(0.99-1.32)$ \\
\hline \multicolumn{5}{|l|}{ Socioeconomic status } \\
\hline High non-manual & 4.8 & 1.00 & 5.8 & 1.00 \\
\hline Medium non-manual & 6.6 & $1.40(1.00-1.94)$ & 8.5 & $1.50(1.13-1.98)$ \\
\hline Low non-manual & 14.1 & $3.23(2.28-4.59)$ & 16.6 & $3.20(2.41-4.23)$ \\
\hline Skilled bluecollar & 13.9 & $3.18(2.34-4.32)$ & 22.1 & $4.57(3.46-6.03)$ \\
\hline Unskilled bluecollar & 19.4 & $4.74(3.53-6.35)$ & 22.9 & $4.78(3.65-6.26)$ \\
\hline Employer/farmer & 11.3 & $2.50(1.80-3.49)$ & 13.4 & $2.49(1.76-3.53)$ \\
\hline Early retired & 31.0 & $8.85(6.22-12.60)$ & 29.9 & $6.87(5.07-9.30)$ \\
\hline Unemployed & 25.8 & $6.87(4.80-9.83)$ & 23.9 & $5.04(3.65-6.97)$ \\
\hline Student & 6.9 & $1.47(0.97-2.23)$ & 11.1 & $2.00(1.46-2.75)$ \\
\hline Pensioner & 9.4 & $2.05(1.53-2.74)$ & 11.0 & $1.99(1.52-2.61)$ \\
\hline No information on SES & 13.7 & $3.12(2.18-4.47)$ & 18.9 & $3.76(2.68-5.25)$ \\
\hline Long term sick leave & 29.3 & 8.19 (4.88-13.75) & 26.6 & $5.82(3.86-8.79)$ \\
\hline \multicolumn{5}{|l|}{ Emotional support } \\
\hline High & 10.4 & 1.00 & 13.6 & 1.00 \\
\hline Low & 14.7 & $1.49(1.32-1.67)$ & 17.9 & $1.39(1.25-1.54)$ \\
\hline \multicolumn{5}{|l|}{ Instrumental support } \\
\hline High & 10.3 & 1.00 & 13,4 & 1.00 \\
\hline Low & 16.3 & $1.68(1.49-1.90)$ & 19.9 & $1.60(1.44-1.78)$ \\
\hline \multicolumn{5}{|l|}{ Trust } \\
\hline High & 9.7 & 1.00 & 12.4 & 1.00 \\
\hline Low & 16.5 & $1.84(1.63-2.06)$ & 19.5 & $1.72(1.56-1.89)$ \\
\hline \multicolumn{5}{|l|}{ Social participation } \\
\hline High & 8.4 & 1.00 & 11.1 & 1.00 \\
\hline Low & 17.1 & $2.25(2.00-2.52)$ & 21.5 & $2.20(2.00-2.43)$ \\
\hline
\end{tabular}

Men $(n=11,084)$ and women $(n=13,264)$. The public health survey in Skåne 2008. 
Table 3 Prevalence (\%), and crude and age-adjusted odds ratios (OR, $95 \% \mathrm{Cl}$ ) of low social participation

\begin{tabular}{lccc}
\hline \multicolumn{1}{l}{ Social parti-cipation } & & OR $(\mathbf{9 5} \% \mathbf{C l})^{\mathbf{a}}$ & OR $(\mathbf{9 5} \% \mathbf{C l})^{\mathbf{b}}$ \\
\hline Men & & & \\
Heterosexual & 40.0 & 1.00 & 1.00 \\
Bisexual & 43.2 & $1.14(0.80-1.63)$ & $1.36(0.94-1.97)$ \\
Homosexual & 45.9 & $1.27(0.83-1.96)$ & $1.37(0.88-2.13)$ \\
Other & 62.2 & $2.47(1.72-3.55)$ & $2.43(1.67-3.53)$ \\
Women & & & 1.00 \\
Heterosexual & 35.7 & 1.00 & $1.07(0.78-1.46)$ \\
Bisexual & 29.6 & $0.76(0.56-1.02)$ & $0.82(0.50-1.35)$ \\
Homosexual & 27.8 & $0.70(0.42-1.14)$ & $3.21(2.16-4.77)$ \\
Other & 65.5 & $3.42(2.31-5.04)$ &
\end{tabular}

aCrude.

${ }^{\mathrm{b}}$ Adjusted for age.

Men $(N=11,084)$ and women $(N=13,264)$. The public health survey in Skåne 2008.

homosexual women when social participation $(21.0 \%$ attenuation) and the combination of trust and social participation (25.5\% attenuation) were added to the logistic regression model including age, country of birth and socioeconomic status.

\section{Discussion}

Major social capital components such as trust and social participation do not reduce the significantly higher odds ratios of daily smoking in the sexual minority groups, with the exception of the inclusion of social participation in the final model for the "other" group among women. Also, the addition of trust, social participation and their combination to the logistic regression model already including age, country of birth and socioeconomic status substantially reduced the logit for the association between sexual orientation and daily smoking in the "other" sexual orientation group. A substantial attenuation of the logit was also observed for homosexual women when social participation and the combination of social participation and trust were added to the logistic regression model already including age, country of birth and socioeconomic status. No substantial attenuation of the logit (less than $10 \%$ ) was observed for homosexual and bisexual men and bisexual women. One reason is that there seem to be no significant differences in social participation according to sexual orientation for bisexual and homosexual men and women, which is the second finding of our study.

Bisexual men and women have significantly higher odds ratios of daily smoking throughout the analyses compared to heterosexual men and women, respectively, and the odds ratios remain almost unaltered even after the inclusion of the two social capital variables. The two social capital components trust and social participation can thus not account for the high smoking prevalence in this sexual minority group. In sharp contrast, there are distinct differences between the comparisons of the odds ratios of daily smoking between homosexual and heterosexual men as opposed to the corresponding comparison between homosexual and heterosexual women. Significantly higher odds ratios of daily smoking remain among homosexual men throughout the analyses, while no significant odds ratios among homosexual women compared to heterosexual women are observed. Only the odds ratios of daily smoking for the "other" sexual orientation group become not statistically significant in the analyses, for men already after inclusion of birth country and for women after inclusion of social participation. (Table 4). Finally, only the "other" sexual orientation group has higher odds ratios of low social participation among both men and women.

The higher odds ratios of daily smoking among bisexual men and women partly correspond with the finding that bisexual women but not men had statistically increased risk of smoking compared to female and male heterosexuals, respectively, in a study from the UK. The finding of that study also conforms with our finding that homosexual men had increased odds of daily smoking compared to heterosexual men, although homosexual women did not have increased odds of daily smoking in our study in opposition to the finding of the UK study that homosexual women had increased risk of being daily smokers [13]. On the other hand, one study which exclusively concerns women suggests that homosexual women have a lower risk of daily smoking than heterosexual women [12]. Given the small proportion of sexual minorities in most studies, one interpretation is that partly different findings may be explained by methodological concerns such as e.g. selection bias. However, a second more plausible interpretation is that sexual minorities live in different social settings which may explain the observed differences. Such patterns may most probably include various aspects of discrimination, i.e. "the dislike of the unlike" [29]. This second interpretation seems to be the most likely, given the fact that our results correspond well with a Swedish government investigation published in 2005 which showed that homosexual and bisexual men were overrepresented as daily smokers compared to heterosexual men, while the differences in daily smoking between homosexual and bisexual women compared to heterosexual women were smaller [30]. In addition, the finding that the "other" group has significantly lower social participation may be regarded as an aspect of what has sometimes been called the exclusive "dark side of social capital" [31]. Since most daily smokers are recruited during adolescence and in early adulthood [32], it seems that one preventive strategy would be to stop recruitment of daily 


\begin{tabular}{|c|c|c|c|c|}
\hline \multicolumn{5}{|l|}{ Men } \\
\hline & OR $(95 \% \mathrm{Cl})^{\mathrm{a}}$ & OR $(95 \% \mathrm{CI})^{\mathrm{b}}$ & OR $(95 \% \mathrm{CI})^{\mathrm{c}}$ & OR $(95 \% \mathrm{Cl})^{\mathrm{d}}$ \\
\hline Heterosexual & 1.00 & 1.00 & 1.00 & 1.00 \\
\hline Bisexual & $2.28(1.49-3.43)$ & $2.07(1.34-3.18)$ & $2.05(1.33-3.15)$ & $1.95(1.26-3.00)$ \\
\hline Homosexual & $2.21(1.32-3.70)$ & $2.16(1.28-3.63)$ & $2.14(1.27-3.60)$ & $2.13(1.27-3.60)$ \\
\hline Other & $1.56(0.98-2.48)$ & $1.34(0.84-2.14)$ & $1.30(0.81-2.08)$ & $1.22(0.76-1.96)$ \\
\hline \multirow[t]{2}{*}{$\mathrm{R}^{2}$ Nagelkerke } & 0.006 & 0.026 & 0.027 & 0.032 \\
\hline & OR $(95 \% \mathrm{Cl})^{\mathrm{e}}$ & OR $(95 \% \mathrm{Cl})^{f}$ & OR $(95 \% \mathrm{Cl})^{\mathrm{g}}$ & \\
\hline Heterosexual & 1.00 & 1.00 & 1.00 & \\
\hline Bisexual & $1.95(1.26-3.01)$ & $1.89(1.22-2.92)$ & $1.88(1.22-2.92)$ & \\
\hline Homosexual & $2.13(1.27-3.60)$ & $2.17(1.28-3.67)$ & $2.11(1.24-3.58)$ & \\
\hline Other & $1.18(0.73-1.89)$ & $1.13(0.70-1.82)$ & $1.06(0.66-1.72)$ & \\
\hline$R^{2}$ Nagelkerke & 0.035 & 0.047 & 0.064 & \\
\hline \multicolumn{5}{|l|}{ Women } \\
\hline & OR $(95 \% \mathrm{Cl})^{\mathrm{a}}$ & OR $(95 \% \mathrm{Cl})^{\mathrm{b}}$ & OR $(95 \% \mathrm{Cl})^{c}$ & OR $(95 \% \mathrm{CI})^{\mathrm{d}}$ \\
\hline Heterosexual & 1.00 & 1.00 & 1.00 & 1.00 \\
\hline Bisexual & $1.83(1.31-2.55)$ & $1.83(1.31-2.54)$ & $1.71(1.23-2.39)$ & $1.69(1.21-2.35)$ \\
\hline Homosexual & $0.76(0.38-1.52)$ & $0.74(0.37-1.48)$ & $0.72(0.36-1.45)$ & $0.70(0.35-1.41)$ \\
\hline Other & $1.92(1.25-2.95)$ & $1.88(1.22-2.90)$ & $1.78(1.16-2.75)$ & $1.70(1.11-2.63)$ \\
\hline \multirow[t]{2}{*}{$\mathrm{R}^{2}$ Nagelkerke } & 0.003 & 0.003 & 0.006 & 0.010 \\
\hline & OR $(95 \% \mathrm{Cl})^{\mathrm{e}}$ & OR $(95 \% \mathrm{CI})^{f}$ & OR $(95 \% \mathrm{Cl})^{\mathrm{g}}$ & \\
\hline Heterosexual & 1.00 & 1.00 & 1.00 & \\
\hline Bisexual & $1.65(1.18-2.30)$ & $1.59(1.14-2.22)$ & $1.68(1.20-2.36)$ & \\
\hline Homosexual & $0.70(0.34-1.40)$ & $0.71(0.35-1.43)$ & $0.76(0.38-1.54)$ & \\
\hline Other & $1.66(1.08-2.56)$ & $1.59(1.03-2.46)$ & $1.44(0.93-2.23)$ & \\
\hline$R^{2}$ Nagelkerke & 0.014 & 0.024 & 0.048 & \\
\hline
\end{tabular}

${ }^{a}$ Adjusted for age.

${ }^{\mathrm{b}}$ Adjusted for age and country of origin.

'Adjusted for age, country of origin and socioeconomic status.

${ }^{\mathrm{d}}$ Adjusted for age, country of origin, socioeconomic status and emotional support.

eAdjusted for age, country of origin, socioeconomic status, emotional support and instrumental support.

${ }^{\mathrm{f}}$ Adjusted for age, country of origin, socioeconomic status, emotional support, instrumental support and generalized trust in other people.

${ }^{9}$ Adjusted for age, country of origin, socioeconomic status, emotional support, instrumental support, generalized trust in other people, and social participation.

Men $(N=11,084)$ and women $(N=13,264)$. The public health survey in Skåne 2008.

smokers in these minority groups during adolescence and early adulthood.

By including both generalized trust in other people and social participation in this study we theoretically and conceptually adhere to the group of authors such as Coleman and Putnam, and thus emphasize the lowering of social interaction costs for sexual minority groups rather than the individual's struggle for resources within networks. On the other hand, the authors who only acknowledge social networks and not trust as the core component of social capital have had problems operationalizing the struggle for power and resources within the social networks [33]. Our social participation variable is similar to those network variables used by authors within the literature that defines social capital exclusively as social networks. It should be noted that our trust variable conceptually falls within the social capital literature tradition including Coleman and Putnam [22,23] as an aspect of social capital and not primarily an individual trait. Vast differences in trust prevalence ("Do you trust others") between different countries indicate the social and societal as opposed to the individual aspect of generalized trust in other people [34].

Men born abroad have a significantly higher odds ratio of daily smoking compared to men born in Sweden, while the odds ratio of daily smoking among women born abroad is not significantly higher than among women born in Sweden. These patterns have been previously explored, and the results indicate that men born in most other countries than Sweden have higher odds ratios of 
daily smoking, while women born abroad show differing patterns with high odds ratios of daily smoking for women born in e.g. Denmark but low odds ratios for women born in e.g. Arabic speaking countries compared to women born in Sweden [18].

\section{Strengths and limitations}

The 55\% participation rate may theoretically be a source of selection bias, but a previous study on an earlier similar questionnaire with a similar response rate in Skåne showed a good correspondence with population registers concerning composition of the population according to age, gender, education and socioeconomic status, with the exception of under-representation observed among people born in other countries than Sweden [35]. Calculations on the 2008 public health survey in Skåne also display under-representation in the age group 18-34 years $(22.0 \%$ among respondents but $29.0 \%$ in the original sample), and a corresponding over-representation in the $65-80$ year age group (22.9\% of respondents compared to $18.0 \%$ in the sample). Some extent of underrepresentation of men $(45.1 \%$ among respondents and $50.0 \%$ in the sample) was also observed. People with low education were also under-represented to some extent (25.2\% among respondents and $29.3 \%$ in the original sample). However, the more important under-representation among respondents was observed among people born outside Europe $(4.1 \%$ among respondents but $6.9 \%$ in the sample) [36]. The risk of selection bias may still be regarded as acceptably low.

The low proportion of the population which belongs to sexual minorities corresponds well with other national level Swedish data [37] and data from the USA [10]. Still, there may be limitations with items focusing on identity at a given point in time which may plausibly result in under-representation to some extent due to misclassification as a result of some remaining social desirability bias. Also, the fact that aspects of sexual orientation other than identity, e.g. attraction and behavior, were not included in the survey may also be regarded as a limitation [14].

The potential confounders age, birth country, socioeconomic status and social support as well as trust and social participation were adjusted for, and stratification according to sex was conducted.

The tobacco smoking items are valid and reliable for the assessment of tobacco smoking in population studies $[38,39]$. The item concerning sexual orientation has been used previously in a study conducted by a Swedish state authority [37]. The low correlation coefficients between the social support and social capital variables indicate that the variables measure separate dimensions of social support and social capital. The only strong $r=0.568$ correlation between emotional and instrumental support indicates correlation that is high but not high enough to indicate the same dimension of social support.

The cross-sectional study design makes all conclusions involving causation formally impossible.

\section{Conclusions}

Higher and almost unaltered odds ratios of daily smoking compared to heterosexuals are observed for bisexual men and women, as well as for homosexual men throughout the multiple analyses. In contrast, the odds ratios of daily smoking among homosexual women do not significantly differ. Only for the "other" sexual orientation group the odds ratios of daily smoking are reduced to not significant levels compared to heterosexuals among both men and women. Only the "other" sexual orientation group has higher odds ratios of low participation among both men and women compared to heterosexuals.

\section{Competing interests}

The authors declare that they have no competing interests.

\section{Authors' contributions}

$M L$ and MR has contributed to the conception and drafting of the work. ML has analysed the data and written the first draft of the manuscript. ML, JA, BM and MR have contributed to the interpretation and the discussion of the results, and the revision of the contents. All authors have read and approved the final manuscript.

\section{Acknowledgements}

This study was supported by the Swedish Research Council Linnaeus Centre for Economic Demography (VR 79), the Swedish Research Council (Vetenskapsrådet) Grant K2014-69X-22427-01-4, the Swedish ALF Government Grant Dnr M 2011/1816, and the Research Funds of the University Hospital in southern Sweden (SUS).

Received: 9 January 2014 Accepted: 2 June 2014

Published: 6 June 2014

\section{References}

1. Kertzner RM, Meyer IH, Frost DM, Stirratt MJ: Social and psychological well-being in lesbians, gay men, and bisexuals: the effects of race, gender and sexual identity. Am J Orthopsychiatry 2009, 79(4):500-510.

2. Grella CE, Greenwell LM, Mays VM, Cochran SD: Influence of gender, sexual orientation, and need on treatment utilization for substance use and mental disorders: findings from the California Quality of Life Survey. BMC Psychiatry 2009, 9:52.

3. Hyde Z, Comfort J, McManus A, Brown G, Howat P: Alcohol, tobacco and illicit drug use amongst same-sex attracted women: results from the Western Australian Lesbian and Bisexual Women's Health and Well-being Survey. BMC Public Health 2009, 9:317.

4. King M, McKeown E, Warner J, Ramsay A, Johnson K, Cort C, Wright L, Blizard R, Davidson O: Mental health and quality of life of gay men and lesbians in England and Wales: controlled, cross-sectional study. $\mathrm{Br} J$ Psychiatry 2003, 183:552-558.

5. Danielsson M: Folkhälsorapport 2009 (only in Swedish). Stockholm: Socialstyrelsen; 2009.

6. Berg-Kelly K: Adolescent homosexuality: we need to learn more about causes and consequences. Acta Paediatr 2003, 92:141-144.

7. Axelsson J, Modén B, Rosvall M, Lindström M: Sexual orientation and self-rated health: the role of social capital, offence, threat of violence, and violence. Scand J Public Health 2013, 41:508-515.

8. Berglund D, Bergsröm K, Nilsson K: Levnadsvanor. Lägesrapport 2011. Östersund: Statens Folkhälsoinstitut Rapport A; 2012. 03; 2012.

9. Kabir Z, Keogan S, Clarke V, Clancy L: Second-hand tobacco smoke exposure levels and tobacco consumption patterns among a lesbian, 
gay, bisexual and transgender community in Ireland. Public Health 2013, 127:467-472.

10. Dilley JA, Maher JE, Boysun MJ, Pizacani BA, Mosbaek CH, Rohde K, Stark MJ, Simmons KW, Pickle KE, Tang H, Greenwood GL, Cowling DW, Lloyd JC, Roeseler AG, Bal DG: Cigarette smoking among lesbians, gays, and bisexuals: How serious is the problem? Letter to the Editor. Cancer Causes Control 2005, 16(9):1133-1134.

11. Gruskin EP, Hart S, Gordon N, Ackerson L: Patterns of cigarette smoking and alcohol use among lesbian and bisexual women enrolled in a large health maintenance organization. Am J Public Health 2001, 91(6):976-979

12. Dibble SL, Roberts SA, Nussey B: Comparing breast cancer risk between lesbians and their heterosexual sisters. Women's Health Issues 2004, 14:60-68.

13. King $M$, Nazareth I: The health of people classified as lesbian, gay and bisexual attending family practitioners in London: a controlled study. BMC Public Health 2006, 6:127.

14. Hagger Johnson G, Taibjee R, Semlyen J, Fitchie I, Fish J, Meads C, Varney J: Sexual orientation identity in relation to smoking history and alcohol use at age 18/19: cross-sectional associations from the Longitudinal Study of Young People in England (LSYPE). BMJ Open 2013, 8:3.

15. Jarvis MJ: Patterns and predictors of unaided smoking cessation in the general population. In The Tobacco Epidemic, Vol. 28. Edited by Bolliger CT, Fagerström KO. Basel: Karger; 1997:151-164.

16. Jarvis MJ, Wardle J: Social patterning of individual health behaviours: the case of cigarette smoking. In Social Determinants of Health. 2nd edition. Edited by Marmot M, Wilkinson RG. Oxford: Oxford University Press; 2006:224-237.

17. Lindström M, Hanson BS, Östergren P-O, Berglund G: Socioeconomic differences in smoking cessation: The role of social participation. Scand J Public Health 2000, 28:200-208.

18. Lindström M, Sundquist J: Ethnic differences in daily smoking in Malmö, Sweden: Varying influence of psychosocial and economic factors. Eur J Public Health 2002, 12(4):287-294.

19. Ali SM, Chaix B, Merlo J, Rosvall M, Wamala S, Lindström M: Gender differences in smoking prevalence in different age strata: $\mathrm{A}$ population-based study in southern Sweden. Scand J Public Health 2009, 37(2):146-152.

20. Bourdieu P, Wacquant L: Invitation to Reflexive Sociology. Chicago: Chicago University Press; 1992.

21. Portes A: Social capital: Its origins and applications in modern sociology. Annu Rev Sociol 1998, 24:1-24.

22. Coleman JS: Foundations of Social Theory. Cambridge, Mass, and London England: The Belknap Press of Harvard University Press; 1990.

23. Putnam RD, Leonardi R, Nanetti RY: Making Democracy Work. Civic Traditions in Modern Italy. Princeton, New Jersey: Princeton University Press; 1993.

24. Kawachi I, Kennedy BP, Glass R: Social capital and self-rated health: a contextual analysis. Am J Public Health 1999, 89:1187-1193.

25. Lindström M: Social capital and the miniaturization of community among daily and intermittent smokers: A population-based study. Prev Med 2003, 36(2):177-184

26. Lindström M, Moghaddassi M, Bolin K, Lindgren B, Merlo J: Social capital and daily tobacco smoking: A population-based multilevel analysis in Malmö. Sweden Scand J Public Health 2003, 31(6):444-450.

27. Giordano GN, Lindström M: The impact of social capital on changes in smoking behaviour-a longitudinal cohort study. Eur J Public Health 2011, 21(3):347-354

28. Norusis MJ: SPSS for Windows Advanced Statistics. Release 20.0. Chicago: SPSS; 2012.

29. Scott J, Marshall G: Oxford Dictionary of Sociology. Oxford: Oxford University Press, Third Edition; 2005.

30. Homosexuellas, bisexuellas och transpersoner hälsosituation: The Health Situation of homosexuals, bisexuals and transgender persons. Stockholm: Statens Folkhälsoinstitut (National Institute of Public Health); 2005:19.

31. Putnam RD: Bowling Alone. The Collapse and Revival of American Community. New York: Simon and Schuster; 2000.

32. Hublet A, De Bacquer D, Valimaa R, Godeau E, Schmid H, Rahav G, Maes L: Smoking trends among adolescents from 1990 to 2000 in ten European countries and Canada. BMC Public Health 2006, 10(6):280

33. Giordano GN: Social Capital and Self-Rated Health. Testing Association with Longitudinal and Multilevel Methodologies. Doctoral Dissertation. Malmö: Lund University; 2012.
34. Lindström M: Does social capital include trust? Commentary on Carpiano and Fitterer (2014). Soc Sci Med 2014. in press.

35. Carlsson F, Merlo J, Lindström M, Östergren PO, Lithman T: Representativity of a postal questionnaire survey in Sweden, with special reference to ethnic differences in participation. Scand J Public Health 2006, 34(2):132-139.

36. Lindström $M$, Fridh $M$, Rosvall $M$ : Economic stress in childhood and adulthood, and poor psychological health: Three life course hypotheses. Psychiatry Res 2014, 215:386-393.

37. Boström G, Roth $N$, Nykvist K: Hälsa på lika villkor? Hälsa och livsvillkor bland hbt-personer. Stockholm: Statens Folkhälsoinstitut; 2006:08. Rapport 2006.

38. Steffensen FH, Lauritzen T, Sörensen HT: Validity of self-reported smoking habits. Scand J Prim Health Care 1995, 13:236-237.

39. Wells AJ, English PB, Posner SE, Wagenknecht LE, Perez-Stable EJ: Classification rates for current smokers misclassified as non-smokers. Am J Public Health 1998, 88:1503-1509.

doi:10.1186/1471-2458-14-565

Cite this article as: Lindström et al.: Sexual orientation, social capital and daily tobacco smoking: a population-based study. BMC Public Health 2014 14:565.

\section{Submit your next manuscript to BioMed Central and take full advantage of:}

- Convenient online submission

- Thorough peer review

- No space constraints or color figure charges

- Immediate publication on acceptance

- Inclusion in PubMed, CAS, Scopus and Google Scholar

- Research which is freely available for redistribution 